\title{
(2) OPEN ACCESS \\ Comparison of the characteristics of work-related injuries between older workers and the workers of the conventional working-age in the Republic of Korea, 2010-2014
}

\author{
Kyung-Eun Lee $\odot{ }^{1}$, Jinhee Kim, ${ }^{2,3}$ Jihye Lee ${ }^{1}$
}

\begin{abstract}
- Additional material is published online only. To view please visit the journal online (http://dx.doi.org/10.1136/ injuryprev-2020-043663).

${ }^{1} J u n g b u$ Area Epidemiologic Investigation Team,

Occupational Safety and Health Research Institute, Incheon,

Korea (the Republic of) ${ }^{2}$ Institute on Aging, Ajou University Medical Centre, Suwon, Gyeonggi-do, Korea (the Republic of)

${ }^{3}$ Department of Preventive Medicine and Public Health, Ajou University School of Medicine, Suwon, Gyeonggi-do, Korea (the Republic of)
\end{abstract}

\section{Correspondence to}

Dr Kyung-Eun Lee, Occupational Safety and Health Research Institute, Incheon 21417, Korea (the Republic of); kyeong85@ naver.com

Received 20 January 2020 Revised 26 April 2020 Accepted 2 May 2020 Published Online First 17 July 2020
ABSTRACT

Objective With population ageing, the number of older workers is increasing and the number of work-related injuries in older people is also increasing. Occupational patterns and work-related injury patterns vary with age. This study aimed to compare the incidence and characteristics of work-related injuries in older and younger workers in Korea.

Methods We conducted a retrospective review of the characteristics of workers hospitalised with work-related injuries from January 2010 to December 2014, using data from the National Hospital Discharge In-Depth Injury Survey in South Korea. The analysis was stratified by age into older (aged $\geq 65$ years) and younger (aged 20-64 years) workers.

Results The hospitalisation rate in older workers was double that of younger workers (2014 IRR: 2.06, 95\% Cl 1.53 to 2.76). Compared with workers of conventional working-age, a higher proportion of injured older workers were female $(33.1 \%$ vs $13.6 \%, p<0.001)$, injured due to falls $(40.8 \%$ vs $28.5 \%)$ and injured while working on a farm $(46.5 \%$ vs $6.3 \%, p<0.001)$. In older workers, work-related injuries were seasonal and peaked during summer, but there was little seasonality in injuries among younger workers.

Conclusion Older workers are more vulnerable to work-related injuries and have a different profile of work-related injuries from younger workers. Age-related differences in the injury profile need to be considered when developing workplace injury prevention policies and programmes, and the specific vulnerabilities of older workers need to be addressed.

\section{INTRODUCTION}

The number of older people has been increasing globally due to prolonged life expectancy, which in turn accounts for an increasing proportion of older workers. ${ }^{1}$ In South Korea, which is projected to have the highest life expectancy by year 2030 among 35 developed countries, ${ }^{2}$ the rate of older citizens ( $\geq 65$ years) participating in occupational activities was reported as $31.5 \%$ in 2016 , which was the second highest rate among the Organisation for Economic Co-operation and Development countries. $^{34}$

Despite the high and increasing rate of job participation among workers over the age of 65 , few studies that assess their health status are found due to lack of reliable data in South Korea. Since the retirement age guarantee is 60-65 years old in South Korea, most occupational health studies that use national monitoring systems have defined workers in their $50 \mathrm{~s}$, rather than in their $60 \mathrm{~s}$ or $70 \mathrm{~s}$, as older workers. ${ }^{5}$ The changes in the form of employment after retirement might be one of the main reasons for the lack of health monitoring data for elderly workers in South Korea. In fact, in South Korea, older workers are generally re-employed at small businesses after retirement, where national mandatory systems or policies for workers' health management are not well established.?

The occupational environment and activities influence physical and mental health across all age groups. ${ }^{89}$ Especially in older workers, work-related injuries are more common as the natural ageing process is accompanied by a decrease in physical and cognitive function and accumulation of comorbidities, all of which contribute to different physical responses to external stress in older persons. ${ }^{1011} \mathrm{In}$ a recent systematic review, Nilsson ${ }^{12}$ reported that of the people who died from work-related injuries, $38 \%$ of the total and $60 \%$ of agricultural workers were aged 55 years or older. In spite of their biological and social vulnerabilities, injuries attributed from work environment were rarely studied among workers aged 65 years and older owing to the lack of information being blind spot under the national monitoring systems in South Korea. Therefore, evidence-based studies of the adverse effects of work on health in elderly workers are required, since the health monitoring and management in workers of all ages are considered as public health importance. 589

The aims of this study were to estimate the incidence of hospitalisation from work-related injuries that occurred in 2010-2014, and to compare the characteristics of work-related injuries leading to hospitalisation in older workers with those in conventional working-age.

\section{METHODS}

\section{Study population}

We conducted a cross-sectional survey of adults who had been hospitalised with work-related injuries. The term 'work-related injuries' was defined as injuries that occurred during occupational activities related to income production, excluding violence by others or self-harm. The study period was based on the date of discharge between 1 January 2010 
and 31 December 2014. Patients were sampled using a stratified two-stage cluster sampling method based on the size of the hospital and geographical location, ${ }^{13}$ accounting approximately for $9 \%$ of all inpatients in hospitals with more than 100 beds. Data on inpatients with work-related injuries were extracted from the Korean National Hospital Discharge In-Depth Injury Survey database developed by the Korea Centers for Disease Control and Prevention. Inpatients with work-related injuries were classified into two groups, conventional working-age group aged 20-65 years and older workers aged $\geq 65$ years, to compare the characteristics of work-related injuries between age groups. ${ }^{14}$ On patients with injuries among hospitalised patients, information about the nature of work, the place of injury and details on how the injury took place were noted. The incidence of hospitalisation from work-related injuries among the at-risk population who were actively participating in income production was estimated using economically active population survey data, which are published monthly by Statistics Korea.

\section{Variables}

The study data set contained information about patients' presenting injuries; demographics, including sex, age and financial resources for healthcare expenditure; dates of admission and discharge; admission route; and the list of diagnostic and surgical procedures. The treatment outcome was classified as 'getting better', 'unchanged/getting worse', 'not treated' and 'dead' based on the patient's progression on the health chart. Additionally, patients in the 'unchanged/getting worse' or 'dead' groups were reclassified into the bad prognosis group to be assessed for risk factors. To consider patients' underlying health conditions that could have affected injury progress after hospitalisation, the Charlson Comorbidity Index (CCI) was calculated based on one major and up to 20 minor disease codes, as described by the Korean Classification of Diseases (sixth revised version). ${ }^{15-17}$ The data set contained variables related to the incident that had led to the injury, the types of injuries and the sites where the injury occurred. Traffic injury was distinguished from collision by defining it as injuries caused by vehicles while workers are moving from one place to another. In addition, diagnosis records were used to provide data on the types of injuries (open wounds, strain/dislocation, fracture, nerve/vessel injuries and ruptures of internal organs) and their location (head/neck, spine, trunk, upper extremities, lower extremities and multiple lesions). Injuries were classified according to the classification guidelines published by the Korea Centers for Disease Control and Prevention. In classifying the types of injuries, amputation and crushing injuries were excluded because these were likely to be accompanied by nerve and vessel injuries.

\section{Statistical analysis}

Since the patients in this survey had been sampled using a complex sampling design, all the analyses involved weighting the product of the respective reverse of sampling rates in each hospital and at the patient level. All results, including the rates and statistics testing for significance, were expressed as weighted values, but not weighted when showing the number of patients sampled. To estimate the incidence rate of hospitalisation from work-related injuries, estimates of the number of economically active persons in 2012 (the middle year of the research period) surveyed by Statistics Korea were used as the target population. ${ }^{17}$ The number of inpatients and economically active persons was estimated based on the population structure of the 2010 Korean census results. ${ }^{18}$ We calculated the incidence rate and RR of hospitalisation of the workers from work-related injuries with 95\% CI. ${ }^{19}$ Differences between the conventional working-age group and the older workers in demographics, CCI and injuryrelated characteristics were compared using $\chi^{2}$ tests and MannWhitney tests. Data were analysed using SPSS V.19.0. ${ }^{20}$

The need for informed consent was waived due to the retrospective nature of the study and because data were anonymised prior to analysis.

\section{RESULTS}

Of the 12105 patients hospitalised due to work-related injuries from January 2010 to December 2014, 10692 were among workers of conventional working-age and 1413 among older workers. Among workers of conventional working-age, the annual incidence rate of work injury-related hospitalisations gradually decreased from $372 / 100000$ in 2010 to $305 / 100$ 000 in 2014. Among older workers, the incidence rate of work injury-related hospitalisations was approximately double that of workers of conventional working-age, with no clear secular trend, ranging from $482 / 100000$ in 2011 to $683 / 100000$ in 2013 (figure 1).

There was marked seasonal variation in the incidence rate of hospitalisation due to work-related injuries among older workers, with the incidence rate being highest in June (310.31/100 000 workers, $95 \%$ CI 201.44/100 000 to $478.02 / 100000)$ and lowest in February (129.63/100 000 workers, 95\% CI 57.38/100 000 to $292.89 / 100$ 000) (figure 2); however, there was no marked seasonality in hospitalisations due to work-related injuries in the conventional working-age group.

Table 1 shows worker characteristics according to age group. Compared with the conventional working-age group, a higher proportion of older workers were female. The source of funding for the healthcare costs for work-related injuries varied by age. The Industrial Accident Compensation Insurance, which covers all healthcare expenses, was available to $34.1 \%$ of the conventional working-age group but to only $13.7 \%$ of older workers. The CCI, which indicates predisposing conditions for chronic diseases, was significantly higher in older workers than in the conventional working-age group. The mean duration of hospitalisation was similar in the conventional working-age group and in older workers, even though older workers had a higher rate of surgery during hospitalisation. Almost all of the workers with work injury-related hospitalisations recovered after hospitalisation, but older workers had a higher mortality rate.

The types of injuries and the locations where the injuries occurred are described in table 2. The most common causes of injury in older workers were falls and traffic injuries, while collisions were the most common cause of injury among workers of conventional working-age. The locations where the injuries took place also varied by age. A higher portion of the injuries took place on farms in older workers and in industrial/construction areas in the conventional working-age group.

The types of injuries and their anatomical location are shown in table 3. Older workers had a higher incidence of fractures and spinal injuries than workers of conventional working-age, and workers of conventional working-age had a higher incidence of injuries of the extremities. Multiple injuries were more common in the conventional working-age group.

\section{DISCUSSION}

To the best of our knowledge, this study is the first to assess work-related injuries in workers aged 65 years and over and to compare work-related injuries in older workers and workers 


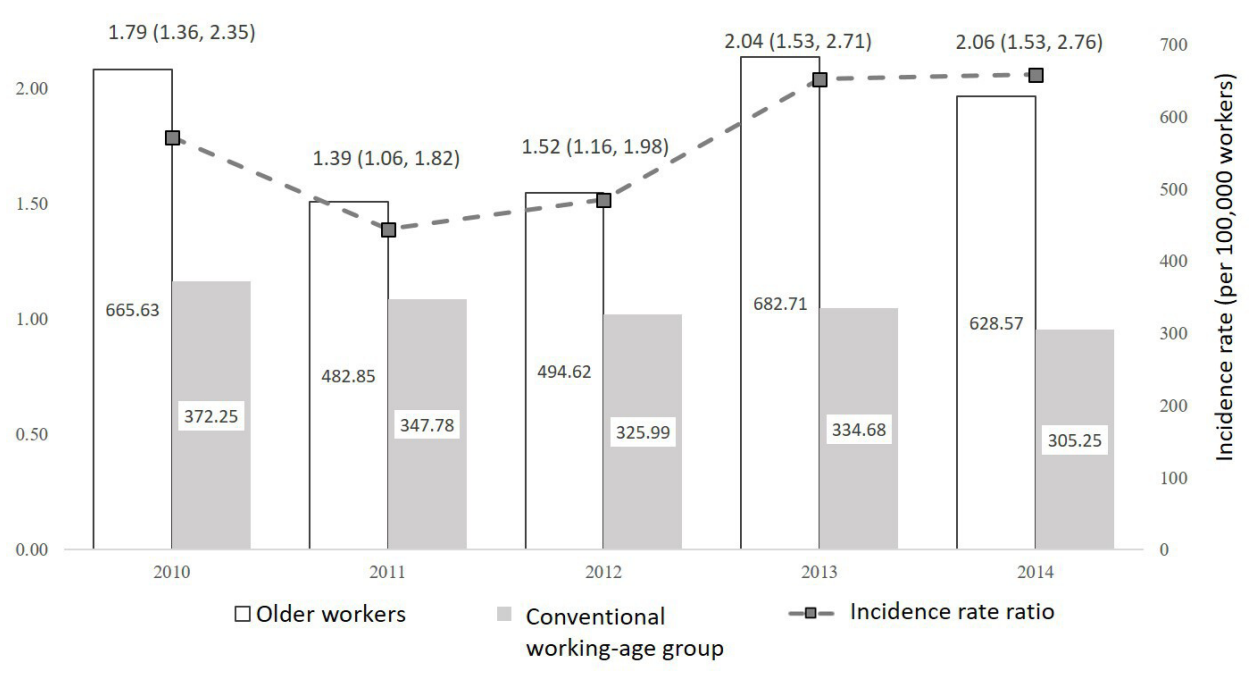

Figure 1 Annual incidence rates and IRRs of hospitalisation due to work-related injuries from January 2010 to December 2014, according to age: older workers, aged $\geq 65$ years; conventional working-age group, aged $<65$ years. Older workers consistently had higher hospitalisation rates than the conventional working-age group. There was a gradual decline in hospitalisation rates among the conventional working-age group over the study period, but there was no secular trend among older workers.

of conventional working-age, using national data in Korea. We found that approximately 600 of 100000 workers who were newly hospitalised for work-related injuries annually were older workers. Furthermore, the incidence rate as well as the number of older workers hospitalised for work-related injuries have been gradually increasing since 2011, in contrast to a decreasing incidence in the conventional working-age group. In addition, older workers were prone to falls and traffic injuries and suffered more fractures in work-related injuries than did the conventional working-age group. The results revealed that working on farms is an important occupational environment risk factor in older

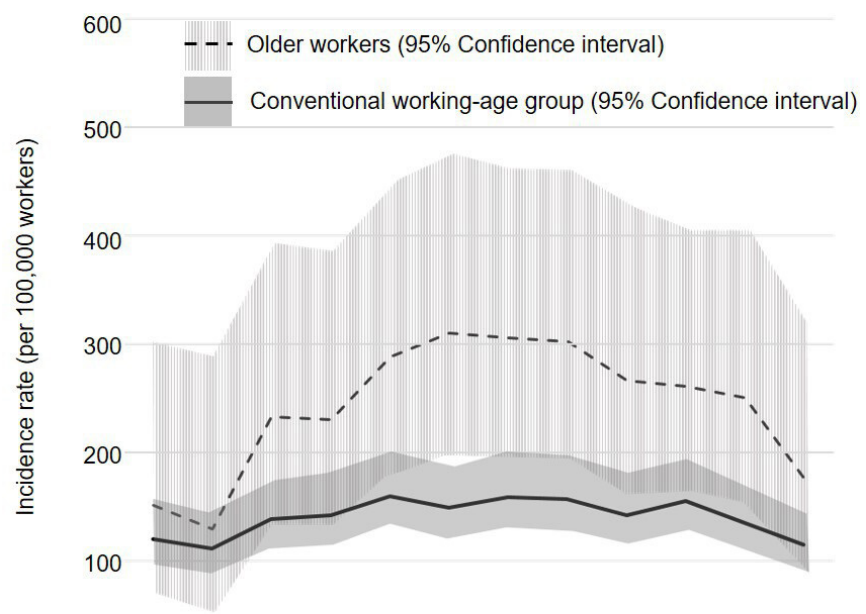

0 Jan Feb Mar Apr May Jun Jul Aug Sep Oct Nov Dec

Figure 2 Incidence rate of hospitalisation due to work-related injuries according to month and age: older workers, aged $\geq 65$ years; conventional working-age group, aged $<65$ years. Hospitalisation rates were highest during the summer months (June-August) and lowest during the winter months (December-February). The seasonality of the work injury-related hospitalisation rate was strong among workers aged $\geq 65$ years and weak among workers aged $<65$ years. workers, and interventions are required for prevention of workrelated injuries in older people working on farms.

Despite differences between countries in the work environment and the working populations, these findings are consistent with those of studies conducted in other countries. Surveillance studies in the US have found that workers over 65 years of age are at particular risk of injuries associated with transportation/driving and have

Table 1 General characteristics of workers hospitalised with workrelated injuries according to age, January 2010-December 2014

\begin{tabular}{|c|c|c|c|}
\hline & $\begin{array}{l}\text { Workers aged } 20-64 \\
(n=10692)\end{array}$ & $\begin{array}{l}\text { Workers aged } \geq 65 \\
(n=1413)\end{array}$ & $P$ value* \\
\hline Sex, $n(\%)$ & & & $<0.001$ \\
\hline Male & $9237(86.4)$ & $966(66.9)$ & \\
\hline Female & 1455 (13.6) & $447(33.1)$ & \\
\hline Admission route, $\mathrm{n}(\%) \dagger$ & & & 0.26 \\
\hline ER & $7095(64.3)$ & $906(60.8)$ & \\
\hline Outpatient clinic & $3590(35.7)$ & $507(39.2)$ & \\
\hline Source of healthcare payment, $n(\%) \dagger$ & & & $<0.001$ \\
\hline $\mathrm{NHI}$ & $5491(49.5)$ & $1060(74.3)$ & \\
\hline Medical aid & $152(1.4)$ & $45(3.5)$ & \\
\hline $\mathrm{IACl}$ & $3487(34.1)$ & $186(13.7)$ & \\
\hline Car insurance & $757(6.8)$ & $94(6.3)$ & \\
\hline Others & $802(8.3)$ & $28(2.2)$ & \\
\hline $\begin{array}{l}\text { Charlson Comorbidity Index, } \\
\text { mean (SE) }\end{array}$ & $0.05(0.002)$ & $0.15(0.012)$ & $<0.001$ \\
\hline $\begin{array}{l}\text { Duration of hospitalisation (days), } \\
\text { mean (SE) }\end{array}$ & $20.62(0.597)$ & $18.96(0.694)$ & 0.06 \\
\hline Required surgery, $\mathrm{n}(\%)$ & & & $<0.001$ \\
\hline Yes & $6269(43.1)$ & $714(47.9)$ & \\
\hline No & $4423(56.9)$ & $699(52.1)$ & \\
\hline Treatment outcome, $\mathrm{n}(\%) \dagger$ & & & 0.001 \\
\hline Getting better & $10313(96.6)$ & $1338(95.0)$ & \\
\hline Unchanged/getting worse & $166(1.7)$ & $20(1.8)$ & \\
\hline Dead & $85(0.6)$ & $29(1.6)$ & \\
\hline Not treated & $125(1.1)$ & $26(1.7)$ & \\
\hline
\end{tabular}

*P values were calculated using the Rao-Scott $\chi^{2}$ tests or Mann-Whitney tests.

tMissing values were excluded from the analysis.

ER, emergency room; IACl, Industrial Accident Compensation Insurance; NHI, National Health Insurance. 
Table 2 Type of injury and the place where the injury took place among workers hospitalised with work-related injuries, according to age, January 2010-December 2014

\begin{tabular}{|c|c|c|c|}
\hline & $\begin{array}{l}\text { Workers aged } \\
20-64 \text { years } \\
(\mathrm{n}=10692) \\
\mathrm{n}(\%)\end{array}$ & $\begin{array}{l}\text { Workers aged } \\
\geq 65 \text { years } \\
(\mathrm{n}=1413) \\
\mathrm{n}(\%)\end{array}$ & P value* \\
\hline Type of injury $\dagger$ & & & $<0.001$ \\
\hline Collision & $3927(38.2)$ & $281(19.6)$ & \\
\hline Traffic injury & $1263(11.6)$ & $312(20.2)$ & \\
\hline Fall & $3121(28.5)$ & $553(40.8)$ & \\
\hline Cut & $742(7.0)$ & $66(5.0)$ & \\
\hline Poisoning/burn & $795(7.8)$ & $91(7.3)$ & \\
\hline Other & 701 (6.8) & $89(7.1)$ & \\
\hline Place where the injury took placet & & & $<0.001$ \\
\hline Residential area/school/sports ground & $233(2.6)$ & $35(2.6)$ & \\
\hline Road & $956(10.6)$ & $186(13.2)$ & \\
\hline Trade/service area & $720(8.4)$ & $42(3.3)$ & \\
\hline Industrial/construction area & $5835(67.0)$ & $339(27.1)$ & \\
\hline Farm & $542(6.3)$ & $515(46.5)$ & \\
\hline Other & $431(5.0)$ & $84(7.2)$ & \\
\hline
\end{tabular}

${ }^{*} \mathrm{P}$ values were calculated using Rao-Scott $\chi^{2}$ tests.

tMissing values were excluded from the analysis.

more disabling fracture injuries and a higher work-related injury mortality rate than the conventional working-age group. ${ }^{51}$ The incidence rate of work-related injuries among older farm workers in our study was comparable with that of farm workers in the US, but the injury-related mortality rate among older farm workers in our study was higher than the overall farming-related mortality rate in the US. ${ }^{22}$ This may be because our study only included workers with injuries that were sufficiently severe to require hospitalisation. The high incidence of falls among older workers could be explained by functional decline in balance and sensory system including locomotor adaptation due to ageing. ${ }^{511}$ The significantly higher incidence of spine and trunk injuries in older workers in our study could be due to falls being an important cause of work-related injuries in older workers. ${ }^{23}$ Høst et al ${ }^{24}$ reported that the elderly were likely to perceive accidental falls as insignificant and irrelevant without realising that accidental falls could be a health problem. This lack of health literacy can also result

Table 3 Physical characteristics of work-related injuries among workers hospitalised with work-related injuries, according to age, January 2010-December 2014

\begin{tabular}{|c|c|c|c|}
\hline & $\begin{array}{l}\text { Workers aged } 20-64 \\
\text { years } \\
(n=10692) \\
n(\%)\end{array}$ & $\begin{array}{l}\text { Workers aged } \geq 65 \\
\text { years } \\
(n=1413) \\
n(\%)\end{array}$ & P value* \\
\hline \multicolumn{4}{|l|}{ Anatomical location } \\
\hline Head/neck & $2488(20.5)$ & $289(18.5)$ & 0.113 \\
\hline Spine & 1958 (18.7) & $376(28.6)$ & $<0.001$ \\
\hline Trunk & $1876(16.7)$ & $308(21.2)$ & $<0.001$ \\
\hline Upper extremities & $4739(46.0)$ & $423(30.2)$ & $<0.001$ \\
\hline Lower extremities & $2759(26.3)$ & $388(27.3)$ & 0.424 \\
\hline Multiple locations & $420(4.6)$ & $33(2.7)$ & 0.006 \\
\hline \multicolumn{4}{|l|}{ Type of injury } \\
\hline Open wound & $1951(18.1)$ & $194(13.9)$ & $<0.001$ \\
\hline Strain/sprain/dislocation & $2265(22.8)$ & $237(18.5)$ & $<0.001$ \\
\hline Fracture & $5344(48.7)$ & $844(58.3)$ & $<0.001$ \\
\hline Nerve or vessel injury & $567(5.3)$ & $46(2.7)$ & $<0.001$ \\
\hline Rupture of an internal organ & $1614(13.3)$ & $294(18.4)$ & $<0.001$ \\
\hline
\end{tabular}

*P values were calculated using Rao-Scott $\chi^{2}$ tests. in older workers failing to comply with interventions such as fall prevention programmes that require voluntary participation. ${ }^{12} 24$ Further studies are therefore required to identify new safety practices, which operate sustainably in older workers, not only for decreasing hospitalisation rates, but for encouraging healthy ageing in the older population.

Our results also showed that the incidence rate of work-related injuries had seasonality, where the incidence rate increased from June to August when the ambient temperature and precipitation were high in Korea. However, seasonal variation in injury events in the older population has not been observed in previous studies. $^{25}$ Rather, the number of patients with falls, which were the most common type of injury in our study, increased in the winter, showing a negative correlation with the ambient temperature in the older population. ${ }^{2627}$ Other studies which have shown seasonal variations with similar patterns to our study have found that seasonal injuries were prevalent in outdoor workers. A study conducted in Denmark found that the incidence of unintentional injuries while farming displayed seasonal variation, with the summer and the autumn having a double relative incidence compared with the winter and the spring. ${ }^{28}$ Because $67 \%$ of the older workers work as day labourers or in agricultural, forestry and fishery according to the national statistics in Korea, ${ }^{17}$ these occupational activities might attribute to additional incidences of injury during the summer season in older workers while showing different seasonality with the general population. Therefore, a strategic prevention programme for reducing work-related injuries could be applied targeting specific seasons to promote compliance and efficiency in older workers.

This study has several limitations that need to be considered while interpreting the findings. First, because the survey database used in this study was developed using patients' medical records during admission, residual confounding cannot be ruled out due to lack of variables, especially information about the nature of job as well as individual behavioural factors that increase vulnerability to injuries. Second, as information related to injuries was recorded based primarily on the diagnosis of doctors, there might be misclassification of whether injuries were related to occupation. However, these uncertainties would not greatly affect our overall results because our study focused on comparisons with work-related injuries in workers of conventional working-age selected with similar sampling biases. Third, the results of this study cannot be generalised to all work-related injuries due to the sampling design which focused on inpatients of hospitals with more than 100 beds. As described above, incidence estimation of work-related injuries is likely to be an underestimate of the true incidence of all work-related injuries because workers with mild injuries that did not require hospitalisation or those who were admitted to small hospitals were excluded. However, considering the lack of information to be assessed in older workers due to the low rate of workers' compensation claims, the results of this study could rather contribute to providing comprehensive evidence on older workers with workrelated injuries, including undetected cases on workers' compensation data. In addition, the control group covered a wide range of workers aged 20-64. Because workers in their 20s are likely to have different injury patterns compared with workers nearing the retirement age of 50-64, the results should be interpreted carefully according to specific age groups. However, the general characteristics and incidence patterns were quite similar among the conventional working-age group, showing similar trend with increasing age except for hospitalisation period, which showed differences in characteristics after stratifying age into 20-34, $35-49,50-64$ and +65 groups (online supplementary file). We 
assure that this classification bias would not affect the overall results of this study in terms of evaluating and representing the characteristics of work-related injuries among elderly workers.

This study investigated the increasing rate of hospitalisation from work-related injuries and the associated environmental and health factors in older workers. The results highlight the necessity of efforts to apply appropriate health management programmes targeting older workers as an increasing labour force. Notably, the prevention programme on falls, traffic injuries and complications of fractures targeting farming seasons could be considered as one of the most effective ways to reduce work-related injuries in older workers. Furthermore, it is necessary to do further research on the working process and related injuries to prepare and educate all stakeholders about the behavioural responses suitable for different types of work activities in older workers.

\section{What is already known on the subject}

- In the Republic of Korea, the number of older workers is increasing.

- Job profiles vary according to age, and work injury patterns are also likely to vary according to age.

\section{What this study adds}

- Among workers aged $\geq 65$ years in the Republic of Korea, the incidence rate of work-injury-related hospitalisations in 2010-2014 was approximately double that of workers of conventional working-age.

- Compared with workers of conventional working-age, the proportion of female workers was higher among older workers hospitalised for work-related injuries.

- Among older workers, work-related injuries were seasonal and the incidence peaked during the summer months.

- Almost half of the injuries in older workers took place on farms, while industry/construction sites were the most common locations in the conventional working-age group.

- Older workers are vulnerable to work-related injuries and their injury profile differs from that of workers of conventional working-age; therefore, policies for injury prevention from workplace and programmes need to cater to the distinct needs of older workers.

Acknowledgements We thank the Korea Centers for Disease Control and Prevention for providing the study data set.

Contributors K-EL designed the study, conducted the statistical analyses and wrote the manuscript. JK participated in the interpretation of the analyses and helped in drafting the paper. JL participated in the interpretation of the analyses and critically appraised the manuscript.

Funding The authors have not declared a specific grant for this research from any funding agency in the public, commercial or not-for-profit sectors.

Competing interests None declared.

Patient and public involvement Patients and/or the public were not involved in the design, or conduct, or reporting, or dissemination plans of this research.

Patient consent for publication Not required.

Ethics approval This study protocol was approved by the appropriate institutional review board.

Provenance and peer review Not commissioned; externally peer reviewed.

Data availability statement Data may be obtained from a third party and are not publicly available. The data that support the findings of this study are available from Korea Centers for Disease Control and Prevention. Restrictions apply to the availability of these data, which were used under licence for this study. Data are available at http://www.nih.go.kr/board.es?mid=a20507030000\&bid=0020\&act= view\&list_no=138559\&tag=\&nPage=3 with permission from the Korea Centers for Disease Control and Prevention.

Open access This is an open access article distributed in accordance with the Creative Commons Attribution Non Commercial (CC BY-NC 4.0) license, which permits others to distribute, remix, adapt, build upon this work non-commercially, and license their derivative works on different terms, provided the original work is properly cited, appropriate credit is given, any changes made indicated, and the use is non-commercial. See: http://creativecommons.org/licenses/by-nc/4.0/.

\section{ORCID iD}

Kyung-Eun Lee http://orcid.org/0000-0001-5112-7747

\section{REFERENCES}

1 Fraade-Blanar LA, Sears JM, Chan KCG, et al. Relating older workers' injuries to the mismatch between physical ability and job demands. J Occup Environ Med 2017:59:212-21.

2 Kontis V, Bennett JE, Mathers CD, et al. Future life expectancy in 35 industrialised countries: projections with a Bayesian model ensemble. Lancet 2017;389:1323-35.

3 Lee J, Smith JP. Work, retirement, and depression. J Popul Ageing 2009;2:57-71.

4 Labour force statistics in OECD countries, 2018. Available: http://stats.oecd.org/Index. aspx?Queryld=64196; [Accessed 19 Feb 2018].

5 Farrow A, Reynolds F. Health and safety of the older worker. Occup Med 2012;62:4-11.

6 Rhee KY, Choe SW, Kim YS, et al. The trend of occupational injuries in Korea from 2001 to 2010. Saf Health Work 2013:4:63-70.

7 OECD. Ageing and employment Policies/Vieillissement et politiques de l'emploi: Korea, 2004.

8 Cooper CL, Marshall J. Occupational sources of stress: A review of the literature relating to coronary heart disease and mental ill health. In: From stress to wellbeing volume 1. London: Palgrave Macmillan, 2013.

9 Goetzel RZ, Long SR, Ozminkowski RJ, et al. Health, absence, disability, and presenteeism cost estimates of certain physical and mental health conditions affecting U.S. employers. J Occup Environ Med 2004;46:398-412.

10 Fried LP, Tangen CM, Walston J, et al. Frailty in older adults: evidence for a phenotype. J Gerontol A Biol Sci Med Sci 2001;56:M146-57.

11 Shumway-Cook A, Guralnik JM, Phillips CL, et al. Age-Associated declines in complex walking task performance: the walking InCHIANTI toolkit. J Am Geriatr Soc 2007; 55:58-65.

12 Nilsson K. Interventions to reduce injuries among older workers in agriculture: A review of evaluated intervention projects. Work 2016:55:471-80.

13 Hong J, Lee W-K, Kim MK, et al. Effect of comorbidity on length of hospital stay and in-hospital mortality among unintentionally injured patients. Accid Anal Prev 2013:52:44-50.

14 Kim YS, Kim BH, Kim HM. A study on occupational accident of older workers and vulnerable working condition. Health Soc Sci 2014;35.

15 Quan H, Li B, Couris CM, et al. Updating and validating the Charlson comorbidity index and score for risk adjustment in hospital discharge Abstracts using data from 6 countries. Am J Epidemiol 2011;173:676-82.

16 Sundararajan V, Henderson T, Perry C, et al. New ICD-10 version of the Charlson comorbidity index predicted in-hospital mortality. J Clin Epidemiol 2004;57:1288-94.

17 Statistics Korea. Monthly report on the economically active population survey. Daejeon (Korea): Statistics Korea, 2014.

18 Korea Statistics. Population and housing census. Daejeon (Korea): Korea Statistics, 2010.

19 Altman DG, Bland JM. Interaction revisited: the difference between two estimates. BMJ 2003:326:219.

20 IBM Corp. SPSS. version 19.0 for windows. Armonk (NY): IBM Corp, 2010.

21 Konstantinidis A, Talving P, Kobayashi L, et al. Work-Related injuries: injury characteristics, survival, and age effect. Am Surg 2011;77:702-7.

22 Myers JR, Layne LA, Marsh SM. Injuries and fatalities to U.S. farmers and farm workers 55 years and older. Am J Ind Med 2009:52:185-94.

23 Jabbour $\mathrm{P}$, Fehlings $\mathrm{M}$, Vaccaro $\mathrm{AR}$, et al. Traumatic spine injuries in the geriatric population. Neurosurg Focus 2008;25:E16.

24 Høst D, Hendriksen C, Borup I. Older people's perception of and coping with falling, and their motivation for fall-prevention programmes. Scand J Public Health 2011;39:742-8.

25 Mondor L, Charland K, Verma A, et al. Weather warnings predict fall-related injuries among older adults. Age Ageing 2015;44:403-8.

26 Bulajic-Kopjar M. Seasonal variations in incidence of fractures among elderly people. Inj Prev 2000;6:16-19.

27 Masud T, Morris RO. Epidemiology of falls. Age Ageing 2001;30:3-7

28 Rasmussen K, Carstensen O, Lauritsen JM. Incidence of unintentional injuries in farming based on one year of Weekly registration in Danish farms. Am J Ind Med 2000;38:82-9. 